\title{
Physico-Chemical, Microbial and Organoleptic Properties of Yoghurt Fortified with Tomato Juice
}

\author{
Olabisi Theresa Ademosun ${ }^{1, *}$, Kolawole Oluseyi Ajanaku ${ }^{1}$, Abiodun Humphrey Adebayo ${ }^{2}$, \\ Mary Omolara Oloyede ${ }^{1}$, Daniel Uche Okere ${ }^{2}$, Anuoluwa Abimbola Akinsiku ${ }^{1}$, \\ Samuel Oluwakayode Ajayi ${ }^{1}$, Christianah Oluwatoyin Ajanaku ${ }^{1}$, \\ Titilope Modupe Dokunmu ${ }^{2}$, Ayotunde Olayinka Owolabi ${ }^{3}$ \\ ${ }^{1}$ Department of Industrial Chemistry, Covenant University, Km 10, Idiroko Road, Canaanland, Ota, Nigeria \\ ${ }^{2}$ Department of Biochemistry, Covenant University, Km 10, Idiroko Road, Canaanland, Ota, Nigeria \\ ${ }^{3}$ Department of Agriculture Economics and Extension, Landmark University, Omu Aran \\ *Corresponding author: olabisi.ademosun@covenantuniversity.edu.ng
}

Received October 03, 2019; Revised November 15, 2019; Accepted November 27, 2019

\begin{abstract}
The world is currently trending towards the discovery of foods that can also serve as nutraceuticals which are highly beneficial to human health. Fortification of yoghurt with fresh tomato juice has shown to incorporate lycopene into the yoghurt, which in turn, increased the nutritional benefit of the yoghurt. Tomato juice was added as increasing levels of $0,50,100,150$ and $200 \mathrm{w} / \mathrm{w} \%$ to plain yoghurt. Ash, carbohydrate, moisture $\mathrm{pH}$, viscosity and lycopene content were all analyzed using standard methods. Results showed that ash and carbohydrate content of the yoghurt improved in direct proportion with fortification. Lycopene content also increased $(1.50-9.24 \mathrm{mg} / \mathrm{kg})$ as enrichment with fresh tomato juice increased. Viscosity reduced drastically as fortification increased, colour and texture of the yoghurt also changed; however, sample B ( $50 \%$ tomato juice) showed the best acceptance in respect to the sensory analysis of all the fortified samples. Hence, findings in this research indicated that enrichment of yoghurt with fresh tomato juice improved the nutritional indices of the yogurt.
\end{abstract}

Keywords: fortification, lycopene, sensory analysis, antioxidant, yoghurt

Cite This Article: Olabisi Theresa Ademosun, Kolawole Oluseyi Ajanaku, Abiodun Humphrey Adebayo, Mary Omolara Oloyede, Daniel Uche Okere, Anuoluwa Abimbola Akinsiku, Samuel Oluwakayode Ajayi Christianah Oluwatoyin Ajanaku, Titilope Modupe Dokunmu, and Ayotunde Olayinka Owolabi, "PhysicoChemical, Microbial and Organoleptic Properties of Yoghurt Fortified with Tomato Juice." Journal of Food and Nutrition Research, vol. 7, no. 11 (2019): 810-814. doi: 10.12691/jfnr-7-11-9.

\section{Introduction}

Yoghurt is widely known by most regulatory agencies globally as a product of milk fermentation that provides certain digested lactose, viable bacterial strains, usually Streptococcus thermophilus and Lactobacillus bulgaricus. It contains essential nutrients such as protein, calcium, potassium, zinc, phosphorus, and vitamins $B_{2}$ and $B_{12}$, which can also serve as a means for fortification [1]. Its nutritional benefits can be compared to that of milk because individuals who are fairly lactose bigoted can take pleasure in yoghurt without adverse effects, because the bacteria culture during yoghurt production automatically converts the lactose in the milk precursor to lactic acid [2].

The first record of the production of yoghurt was in the Middle East when herdsmen carried milk in an intestinal gut bag. It was found that the interaction between the milk and the intestinal juice made the milk to curdle and sour, stabilizing it and allowing for conservation of a dairy product for longer periods [3]. The production of yoghurt was later spread all over the world. It is called Dahi in
India, Mast in Iran, Cuajada in Spain, Iogurte in Brazil, Matsoni in Georgia, Coalhada in Portugal and Roba in Sudan [4].

The appreciable probiotic characteristics, the bioavailability of nutrients, high digestibility and the ability to solve lactose intolerance in related patients helps yoghurt to be classified amongst the healthy food. It has also excelled as one of the most consumed healthy and nutritious food around the world, which also offers the potential to deliver nutritious components to the human diet [5]. Additionally, it also helps in the reduction of gastrointestinal disorders (irritable and inflammatory bowel diseases), helps in weight control, fight against infections and boost immunity [6]. Moreso, yoghurt is known to combat constipation, treatment of diarrhoea and dysentery by curbing the growth of the bacteria that causes these ailments, its anti-carcinogenic effect and ability to lower blood cholesterol is also on record [7]. Furthermore, yoghurt helps in the promotion of good gums, facilitates the absorption of calcium thereby preventing osteoporosis, possibly because of the probiotic effect of lactic acids presents in yoghurt [8]. As a result of the above health benefits linked with intake of yoghurt, there is a rising 
trend in yoghurt consumption all over the world. Nevertheless, the need for fortification arises because foods fortified are enriched with more nutrients regardless of the nutrients embedded in the whole food.

Some studies have been carried out on fortification of yoghurt. Examples include the production of yoghurt enriched with coconut-cake [9]. The result showed yoghurt enriched with coconut cake has high nutritive value in terms of protein, carbohydrate, ash content and fibre content compared to the plain yoghurt. The production of yoghurt spiced with graded levels of watermelon (Citrullus lanatus) juice was studied by [10]. The outcome showed an increase in the fibre and micronutrient content of the spiced yoghurt with an increase in watermelon juice but decrease in protein, ash and fat content with increase in watermelon juice. [11] reported the fortification of yoghurt with different fruits (strawberry, orange and grape) at different level (5\%, 10\% and 15\%). The research showed the quality of the yoghurts improved compared to plain yoghurt and yoghurt fortified with $10 \%$ orange was the best in quality among others. Less nutritious foods, poor nourishments and unhygienic homes predispose humans to contaminations, diseases, high mortality and malnutrition [12].

Globally, Tomatoes (Solanum lycopersicum) are categorized as one of the most consumed vegetables by humans. They contain nutrients and phytochemicals such as vitamin C, vitamin A (as carotenoids), fibre, potassium, and the antioxidant such as lycopene which is also responsible for their red pigments. Tomato is ranked as the third vital vegetable cultivated in the world and also, one of the most consumed fruit in the world [13]. Tomatoes are the richest source of lycopene which helps in reducing the risk of some cancers. Lycopene is the main dietary carotenoid in tomatoes [14]. It is found in substantial amount in human serum and tissues when tomato products are consumed regularly. Some researchers have reported lycopene for markers of cardiovascular disease, cancers, osteoporosis, ultraviolet light-induced skin erythema, cognitive function and body weight [15]. Carotenoids such phytoene, phytofluene, z-carotene, b-carotene, neurosporene, and lutein are also known to be embedded in tomatoes and these carotenoids have gained recognition for promoting health. Thus, recent research identifies the importance of the whole tomato; and hence, the study on the role of tomatoes in health and disease risk reduction encompasses beyond antioxidant function to include other defending mechanisms such as antithrombotic and antiinflammatory functions [16].

The distinctive constituents of tomatoes which helps in the promotion of good health and also, ability to also serve as a low energy-dense food contribute greatly to their culinary role in diets. Thus, this study aims to determine the nutritional, functional, sensory and microbial properties of plain yoghurt fortified with tomato juice.

\section{Materials}

Freshly prepared yoghurt was purchased at Hebron Yoghurt Plc, Canaanland Ota, Ogun State, Nigeria while fresh matured tomatoes were also purchased at Ota Market, Ogun State, Nigeria.

\section{Methods}

\subsection{Preparation of Tomato Juice}

The tomatoes were sorted to remove the bruised or bad ones, thoroughly washed in distilled water for six (6) times to remove dirt. Afterwards, they were transferred into a sterilized Rite Tek (BL- 210) blender cup and ground for 10 minutes. The blended sample was made to pass through a clean vibrating shaker of $500 \mathrm{~nm}$ sieve to separate the juice from the chaff. The juice was stored in a sterilized bottle and kept in the fridge at $-28^{\circ} \mathrm{C}$ till use.

\subsection{Preparation of Tomato-Yoghurt}

Yoghurt (200 mL each) was measured into five (5) sterilized bottles. Each bottle containing the yoghurt was fortified with a varied volume of tomato juice $(0,50,100$, 150 and $200 \mathrm{~mL}$ ) and labelled as group A, B, C, D, and E respectively as shown in the batch composition in Table 1. The blends were mixed and shook properly in air-tight bottles to ensure maximum mixing, the samples were then labelled and kept in the fridge at $-28^{\circ} \mathrm{C}$ for further chemical analysis.

Table 1. Batch Composition of Tomato Yoghurt

\begin{tabular}{lccccc}
\hline Samples & A & B & C & D & E \\
\hline Yoghurt $(\mathbf{m L})$ & 200 & 200 & 200 & 200 & 200 \\
Tomato juice $(\mathbf{m L})$ & 0 & 50 & 100 & 150 & 200 \\
\hline
\end{tabular}

\subsection{Chemical Analysis of Tomato Yoghurt}

Moisture, ash and protein content of the samples were analyzed using [17] methods of analysis. Carbohydrate content was determined using the anthrone method. The absorbance of the standard (glucose solution) was plotted against the concentration of the standard to determine the carbohydrate (CHO) concentration of the blends. Titratable acidity was determined using [18] method, $\mathrm{pH}$ was determined using an unican $\mathrm{pH}$ meter which was previously standardized with buffer solutions of $\mathrm{pH} 4$ and $\mathrm{pH}$ 9. Viscosity was determined using a Brookfield viscometer (Brookfield viscometer DVII, USA) with a spindle no. 4 and 3 rates per minute rotation speed at $6{ }^{\circ} \mathrm{C}$. Results recorded in centipoises (cP) after $50 \mathrm{~s}$ of shearing. Lycopene content was estimated using the method of [19]. Sensory evaluation was done by experts from yoghurt manufacturing industry using a 5-point Hedonic index of taste, colour, aroma, appearance and overall acceptability. All reagents were of analytical grade and were used as received without further purification.

\subsection{Microbial Culture}

The different fortified batches of yoghurt were inoculated on three growth media (Nutrient agar, Eosin Methylene Blue and Salmonella-Shigella agar) and incubated aerobically at $37^{\circ} \mathrm{C}$ for $18-24$ hours, so as to determine the growth of bacteria. Microbial colonies were observed morphologically and counted using standard methods. The growth in the different plates were counted and recorded and compared between groups. 


\subsection{Statistical Analysis}

Data was recorded using Microsoft Excel and analyzed using SPSS version 20. Proportions were recorded in percentages while continuous data were reported as mean \pm standard error of the mean. Analysis of variance (ANOVA) was used to compare mean values within and between groups. Statistical significance was indicated at a $\mathrm{P}$ value $<0.05$.

\section{Results and Discussion}

\subsection{Effect of Tomato Juice on the Proximate Analysis of Yoghurt}

Result of proximate analysis of both yoghurt and the fortified samples is as shown in Table 2. The amount of water present in food samples is a measure of the moisture content. This moisture content is very important in the determination of durability, storage conditions, safety and shelf life of the food. This is because microbial growth in food is enhanced by the amount of moisture present in them. Addition of tomato juice to yoghurt increased the moisture content of the yoghurt from $7.83 \%$ to $9.80 \%$. [20] reported that the higher the percentage of water in yoghurt, the less viscous the yoghurt and this automatically affects the texture and mouthfeel.

Ash content of the samples increased with the addition of tomato juice (7.75- 15.67\%). Sample B showed the highest percentage of protein content and the lowest percentage of carbohydrate content. Protein is known to enhance the formation of antibodies which helps the body fight infections and also, it helps to build, maintain and repair new tissues especially in infants [21].

Yoghurts generally are known to have a low percentage of carbohydrate and this is due to the conversion of carbohydrates (lactose) to lactic acid during fermentation. This particular property of yoghurt makes it an ideal dairy product for patients who cannot tolerate lactose [22].

Table 2. Proximate analysis of the samples

\begin{tabular}{ccccc}
\hline Samples & Moisture (\%) & Ash (\%) & Protein (\%) & Carbohydrate (mL) \\
\hline A & $7.83 \pm 0.2$ & $7.75 \pm 0.3$ & $4.99 \pm 0.2$ & $0.59 \pm 0.2$ \\
B & $8.20 \pm 0.1$ & $9.85 \pm 0.5$ & $6.43 \pm 0.1$ & $0.45 \pm 0.5$ \\
C & $8.50 \pm 0.1$ & $11.87 \pm 0.2$ & $5.74 \pm 0.1$ & $0.65 \pm 0.1$ \\
D & $9.83 \pm 0.5$ & $13.14 \pm 0.1$ & $4.50 \pm 0.3$ & $0.69 \pm 0.1$ \\
E & $9.80 \pm 0.3$ & $15.67 \pm 0.1$ & $5.59 \pm 0.1$ & $0.71 \pm 0.1$
\end{tabular}

\subsection{Effect of Tomato Juice on the Functional Properties of Yoghurt}

Lactobacillus acidophilus is the bacteria often used in yoghurt production. L. acidophilus has a $\mathrm{pH}$ value of 4 and it is responsible for the production of lactase which breaks down lactose (a sugar found in milk) into lactic acid. The conversion of lactose to lactic acid increases the $\mathrm{pH}$ value of yoghurt, which makes it more acidic than milk. The tomato juice has a $\mathrm{pH}$ of 4.3 and the addition of the juice to the yoghurt did not affect the $\mathrm{pH}$ value of the yoghurt. Titratable acidity is the total amount of acid in a sample determined by titration using a standard solution in $\mathrm{NaOH}$. This parameter also determines the freshness of the yoghurt and other fermented drinks, which is a function of the absorption of hydroxyl ions by the protein or salts in the yoghurt. The titratable acidity increases with bacterial acidification and the release of fatty acid, which is due to the breakdown of fats and other lipids by hydrolysis. This result shows that the addition of tomato juice to yoghurt reduced the titratable acidity of the yoghurt.

Lycopene content of the samples increased from $1.50-9.24(\mathrm{mg} / \mathrm{kg}$, as shown in Table 3) and this is so expected because tomatoes consist of lycopene which is the main antioxidant embedded in the fruit. The values obtained in this work were in the range of the lycopene content of some tomato cultivars reported [19]. Fortification of yoghurt with tomato juice in this work drastically reduced the resistance to flow (viscosity) of the yoghurt which in turn increases the flow of the samples. Report has shown that viscosity of yoghurts decreases as storage time increases $[23,24]$, but this present research cannot counter or support this report because all the analysis involved in this study was done in a day and storage time was not put into consideration and this can enhance further studies.

Table 3. pH, titratable acidity, viscosity and lycopene analyses of the samples

\begin{tabular}{ccccc}
\hline Samples & $\mathrm{pH}$ & $\begin{array}{c}\text { Titratable Acidity } \\
\text { (g tartaric/100ml) }\end{array}$ & $\begin{array}{c}\text { Lycopene } \\
\text { content }(\mathrm{mg} / \mathrm{kg})\end{array}$ & $\begin{array}{c}\text { Viscosity } \\
\text { (cP) }\end{array}$ \\
\hline $\mathrm{A}$ & $4.25 \pm 0.1$ & $2.16 \pm 0.1$ & $1.50 \pm 0.1$ & $2,143 \pm 0.1$ \\
$\mathrm{~B}$ & $4.20 \pm 0.1$ & $2.04 \pm 0.2$ & $7.62 \pm 0.2$ & $515 \pm 0.2$ \\
$\mathrm{C}$ & $4.16 \pm 0.2$ & $1.64 \pm 0.1$ & $8.37 \pm 0.2$ & $486 \pm 0.2$ \\
$\mathrm{D}$ & $4.15 \pm 0.5$ & $1.62 \pm 0.2$ & $8.74 \pm 0.2$ & $352 \pm 0.1$ \\
$\mathrm{E}$ & $4.14 \pm 0.2$ & $1.53 \pm 0.5$ & $9.24 \pm 0.1$ & $244 \pm 0.1$ \\
\hline
\end{tabular}

\subsection{Microbial Analysis of Tomato-yoghurt Blends}

Microbial growth in the different batches of fortified yoghurt are reported in Table 4. There was a significantly higher growth of Escherichia coli, gram-negative enteric microorganisms with increasing tomato fortification in Eosin Methylene Blue (EMB) and Salmonella-Shigella (SS) agar but not in nutrient Agar medium. It is noteworthy that at a concentration of 100:200 ml fortification, the microbial growth was notably the lowest in the batches on EMB and SS agar. E. coli is normally present as part of the microflora in the gut with beneficial effects but certain pathogenic strains such as O157:H7 cause severe food poisoning with symptoms ranging from abdominal cramps, vomiting and severe diarrhoea when ingested, thereby causing an imbalance in the microbial ecosystem of the body. With the fortification, the E. coli growth appears to be enhanced with moisture content since no growth was observed in the unfortified samples (group A). Increase in moisture content by the tomato juice might have allowed more suitable growth condition; however, since yoghurt has bactericidal activities, which is dependent on its $\mathrm{pH}$ and low storage temperature [25], microbes may still develop under sub-optimal storage conditions. 
The findings from this study is significant because lactic acid bacteria in yoghurt have previously been shown to possess inhibitory activity towards the growth of pathogenic E. coli and Salmonella sp [25,26], hence fortification with tomato juice at an equal proportion or very high concentration can mitigate this effect, this is demonstrated in group $\mathrm{E}$ with the highest microbial growth of $13.0 \times 10^{-3}$ cells. Similarly, the $\mathrm{pH}$ of yoghurt which ranges from $4.14-4.25$ contributes relatively to the probiotic activities enjoyed by its consumption. In another study, in vitro survival of pathogenic E. coli strain in yoghurt over 3 weeks of storage at $15^{\circ} \mathrm{C}$ was reported to be due to colanic acid in E. coli; which abates the stress induced on the bacteria during production [23]. Although medicinal properties of this drink was not directly tested, it can be inferred based on several antioxidants present in fortified drink from tomatoes and probiotic properties of yoghurt that this drink will provide many health benefits, it is safe and easily digestible for adults, ill, malnourished children or lactose intolerant persons; this is recommended for further in- vivo studies.

Table 4. Microbial culture in different media for the fortified yoghurt samples

\begin{tabular}{cccc}
\hline Samples & $\begin{array}{c}\text { EMB Agar } \\
(\mathrm{CFU} / \mathrm{ml})\end{array}$ & $\begin{array}{c}\text { SS Agar } \\
(\mathrm{CFU} / \mathrm{ml})\end{array}$ & $\begin{array}{c}\text { Nutrient Agar } \\
(\mathrm{CFU} / \mathrm{ml})\end{array}$ \\
\hline $\mathrm{A}$ & $\mathrm{NG}$ & $\mathrm{NG}$ & $\mathrm{NG}$ \\
$\mathrm{B}$ & $5.0 \times 10^{-3}$ & $3.0 \times 10^{-3}$ & $3.0 \times 10^{-3}$ \\
$\mathrm{C}$ & $2.6 \times 10^{-3}$ & $2.6 \times 10^{-3}$ & $8.0 \times 10^{-3}$ \\
$\mathrm{D}$ & $5.8 \times 10^{-3}$ & $5.2 \times 10^{-3}$ & $2.4 \times 10^{-3}$ \\
E & $4.9 \times 10^{-3}$ & $4.7 \times 10^{-3}$ & $13.0 \times 10^{-3}$ \\
P value & 0.026 & 0.028 & 0.086 \\
\hline
\end{tabular}

$\mathrm{N}=5$ for each group, $\mathrm{NG}-$ no growth.

\subsection{Taste Panel Assessment of Tomato-yoghurt Blends}

Mean sensory evaluation of this study is shown in Table 5. The control showed more of the preferred characteristics and this is due to the fact that the judges are very familiar with the taste of pure yoghurt. Fortification with tomato juice affected the aftertaste, colour and texture of the fortified samples but the taste of the samples remained unaffected as fortification increased. Only sample E showed fair acceptability and this is due to a large amount of tomato juice in the fortified sample. Generally, all the samples were accepted by the judges.

Table 5. Mean sensory evaluation of the yoghurt and the fortified samples

\begin{tabular}{cccccc}
\hline Samples & Aftertaste & Color & Texture & Taste & $\begin{array}{c}\text { Overall } \\
\text { acceptability }\end{array}$ \\
\hline A & 2 & 1 & 3 & 3 & 1 \\
B & 2 & 2 & 3 & 3 & 1 \\
C & 4 & 3 & 4 & 3 & 2 \\
D & 4 & 4 & 4 & 3 & 2 \\
E & 4 & 4 & 4 & 3 & 3 \\
\hline
\end{tabular}

Aftertaste: 1- Persistent, 2- Milky, 3-Sour milk, 4- Astringent, 5-Bitter Color: 1- Whitish, 2- Brownish, 3- Light red, 4- Reddish, 5- Dark red Texture: 1- Compact, 2- Lumpy, 3- Thick, 4- Thin, 5- Coarse

Taste: 1-Creamy, 2- Butter, 3- Sweet, 4-Butter, 5- Sour

O. Acceptability: 1-Very good, 2- Good, 3- fair, 4- Barely acceptable, 5- Not acceptable.

\section{Conclusion}

In this study, tomato juice was used to fortify yoghurt at varied quantities and all the analysis were done in a day. Fortified samples showed high lycopene content, which can meet the daily intake of lycopene by human. In conclusion, our study shows that tomato juice fortification of yoghurt at moderate proportions proves to be highly beneficial with improved taste, nutritional values and retained probiotic activities. Further study is hereby encouraged to deduce the effect of storage time on the samples.

\section{Acknowledgements}

The authors are grateful to the Management of Covenant University, Ota, Ogun State for the sponsorship and state-of-the-art laboratory facilities for the execution of the research work.

\section{References}

[1] Bodot, V., Soustre, Y., and Best, B. (2013). Yogurt Special French National Dairy Council (CNIEL): Scientific and Technical Affairs Division. Available:

http://www.idfdairynutrition.org/Files/media/FactSheetsHP/EXEE N_BofYogurt.p, 2013, Accessed: October 11, 2018.

[2] Vesa, T,H., Marteau, P., and Korpela R. Lactose intolerance. Journal of American College of Nutrition, 129, 2000, 165-175.

[3] Kayanush, J. A., and Douglas, W. O. A 100-Year Review: Ygourt and other cultured dairy products. Journal of Dairy Science, 100, 2017, 9987-10013.

[4] Hadi, H., Mohammad, H., Gholamreza, M., and Mohammad, A. Scientific and technical aspects of yogurt fortification: A review. Food Science and Human Wellness, 4, 2015, 1-8.

[5] Ivanov, G.Y., and Dimitrova, M.R. Functional Yogurt Fortified with Phenolic Compounds Extracted from Strawberry Press Residues and Fermented with Probiotic Lactic Acid Bacteria. Pakistan Journal of Nutrition, 18, 2019, 530-537.

[6] McKinley, M.C. The nutrition and health benefits of yoghurt review, Society of Dairy Technology, 58, 2005, 1- 12.

[7] Kamruzzaman, M., Islam, M.N., Rahman, M., Parvin, S., and Rahman M.F. Evaporation rate of moisture from Dahi (yoghurt) during storage at refrigerated condition. Pakistan Journal of Nutrition, 1, 2002, 209-211.

[8] Kerry, A., Jackson, B., and Dennis, A. Lactose mal-digestion, calcium intake and osteoporosis in African, Asian and HispanicAmericans. Journal of American of College of Nutrition, 20, 2001, 198-205.

[9] Ndife, J., Idoko, F., Garba, R. Production and Quality Assessment of Functional Yoghurt Enriched with Coconut. International Journal of Nutrition and Food Sciences, 3(6), 2014, 545-550.

[10] Diogu, A.O. Production and quality evaluation of spoonable and drinkable yoghurt with watermelon (citrullus lanatus) juice and pulp. M.Sc Thesis. Available: http://hdl.handle.net/123456789/3188, 2016, Accessed: June 15, 2018.

[11] Hossain, M.N., Fakruddin, M., and Islam, M.N. Quality Comparison and Acceptability of Yoghurt with Different Fruit Juices. Journal of Food Process and Technology, 3, 2012, 171.

[12] Ajanaku, K.O, Ademosun, O.T, Mustapha, A, Ajanaku C.O, Olasehinde, G. I, Adekoya O. F, and Ajayi, S. O. Nutritive assessment of sorghum-ogi plantain flour weaning food. IOP Conference Series: Materials Science and Engineering, IOP Publishing, 2019, 509.

[13] Larbat, R., Paris, C., Le B. J, and Adamowicz, S., (2014). Phenolic characterization and variability in leaves stems and roots of microtom and patio tomatoes, in response to nitrogen limitation. Plant Science, 224, 2014, 62-73. 
[14] Yuan, J.M., Ross, R.K., Gao, Y.T., Qu, Y.H., Chu, X.D., and Yu, M.C (2004). Prediagnostic levels of serum micronutrients in relation to risk of gastric cancer in Shanghai, China. Cancer Epidemiology Biomarkers Prevention, 13 (11), 2004, 1772-1780.

[15] Yang, Z., Zhang, Z., Penniston, K., Binkley, N., and Tanumihardjo, S.A. (2008). Serum carotenoid concentrations in postmenopausal women from the United States with and without osteoporosis. International Journal of Vitamin and Nutrition Research 78: 105-111.

[16] Tomas, M., Beekwilder, J., Hall, R. D., Sagdic, O., Boyacioglu, D., and Capanoglu, E. Reno protective effect of the antioxidant curcumin: Recent findings. Redox Biology, 1, 2017, 448-456.

[17] Association of Official Analytical Chemists: AOAC. Official Methods of Analysis of AOAC International. 18th Edition, Gaithersburg, MD, United States of America. 8, 2005, 8-25.

[18] Sadler, G. D., and Murphy, P. A. pH and Titratable Acidity in Food Analysis. 3rd edition, 2003, 207-226.

[19] Mohammed, S. M., Abdurrahman, A. A., and Attahiru, M. Proximate Analysis and Total Lycopene Content of Some Tomato Cultivars Obtained from Kano State, Nigeria. Chemistry Search Journal 8(1), 2017, 64-69.

[20] Ahmad, J. Quality characteristics of plain yoghurt made from standardize Buffalo milk. M.Sc Thesis. University of Agric
Faisalabad, 1994.

[21] Ajanaku, K.O., Ademosun, O.T., Siyanbola, T.O., Akinsiku, A.A. Ajanaku, C.O., and Nwinyi, O.C. Improving Nutritive Value of Maize-Ogi as Weaning Food Using Wheat Offal Addition. Current Research in Nutrition and Food Science, 5(3), 2017, 206-213.

[22] Ehirim, F. N., and Ndimantang, B. E. Production and Evaluation of yoghurt from cow - say milk Blends. Journal of Agriculture and food science, 3 (1), 2004, 33-39.

[23] Lee, S.M., Chen J. Survival of Escherichia coli O157:H7 in set yogurt as influenced by the production of an exopolysaccharide, colanic acid. Journal of Food Protection, 67(2), 2004, 252-255.

[24] Supavititpatana. P., Wirjantoro, T.I. and Raviyan, P. (2010). Characteristics and shelf-life of corn milk yogurt. Journal of Nature and Science, 9, 2010, 133-149.

[25] Kotz, C.M., Peterson, L.R., Moody, J.A, Savaiano, D.A., Levitt, M.D. In vitr antibacterial effect of yogurt on Escherichia coli. Digestive Diseases and Sciences, 35(5), 1990, 630-637.

[26] Drago, L.M.R., Gismondo, A., Lombardi, C., and Gozzin, L. Inhibition of in vitro growth of enteropathogens by new Lactobacillus isolates of human intestinal origin. Letters of Applied Microbiology., 153, 1997, 455-463.

(C) The Author(s) 2019. This article is an open access article distributed under the terms and conditions of the Creative Commons Attribution (CC BY) license (http://creativecommons.org/licenses/by/4.0/). 